\title{
ALJAMÍA. BOLETÍN DE INFORMACIÓN BIBLIOGRÁFICA
}

Por

LUIS FERNANDO BERNABÉ PONS

Ha aparecido en Oviedo el segundo número de este Boletín de Información Bibliográfica, editado por el Departamento de Filología Clásica y Románica de la Universidad de Oviedo. Sus propósitos ya aparecían explícitos en el primer número (1989): servir de banco de datos actualizado de cualquier novedad que vaya apareciendo dentro de sus campos de interés, a la vez que llevar a los especialistas la última información que esté surgiendo.

La revista tiene tres campos de interés perfectamente delimitados, pero que hacen que el posible espectro de interesados en su información sea muy amplio: Mudéjares y Moriscos, Textos Aljamiados y Filología Arabo-Románica, con lo que puede resultar interesante por igual a historiadores, romanistas, arabistas, hispanistas, etc.

El boletín se abre con un apartado de NOTICIAS, en que se da cuenta de congresos celebrados o por celebrar, aunque también se recogen nombramientos, homenajes, apariciones de nuevas revistas u órganos científicos, así como los trabajos que se encuentran en prensa y, cosa especialmente interesante, los trabajos que están todavía en fase de preparación.

Después de este apartado, comienza propiamente el trabajo bibliográfico, que está dividido en tres secciones correspondientes con los campos de interés arriba indicados. Dentro de cada una de esas secciones, se ofrecen por orden alfabético las novedades aparecidas en los tres años anteriores a la aparición de cada número del boletín, aunque sin contar el mismo año en que aparece. Si alguna entrada de las reseñadas en estas secciones ofrece un especial interés, se le coloca al final una llamada que remite al último de los apartados del boletín: la sección RECENSIONES.

El Boletín Aljamía tiene como foco centralizador a la Universidad de Oviedo, con la que colabora en su redacción la División Departamental de Estudios Árabes e Islámicos de la Universidad de Túnez y la Universidad de Indiana (USA). 
La dirección está a cargo del profesor Galmés de Fuentes, de la Universidad Complutense de Madrid, siendo sus subdirectores los doctores Míkel de Epalza (Universidad de Alicante), Antonio Vespertino (Universidad de Oviedo) y Abdeljelil Temimi (Universidad de Túnez). La secretaría corre a cargo de la doctora Mercedes Sánchez, de la Universidad de Oviedo, siendo sus redactores el Dr. Toribio Fuente, Juan Busto y Juan Carlos Villaverde, por parte de la Universidad de Oviedo, y Luis F. Bernabé, de la Universidad de Alicante.

El boletín hace un llamamiento a todos los investigadores y estudiosos de estos temas que estén preparando algún trabajo, hagan llegar su noticia a la redacción para poder incluirlo en los próximos números y asegurar su difusión. Del mismo modo, cualquier persona que esté interesada en recibir el boletín, que se distribuye de forma gratuita, puede ponerse en contacto con la misma redacción:

ALJAMÍA. BOLETÍN DE INFORMACIÓN BIBLIOGRÁFICA, Dpto. de Filologia Clásica y Románica. Facultad de Filología. Universidad de Oviedo. 33003 OVIEDO. 